\title{
Experimental testing of methanol sorption on selected coal samples from Upper Silesian Basin
}

\author{
Paweł Baran, Grzegorz Stefan Jodłowski, Andrzej Krzyżanowski, \\ Katarzyna Zarębska
}

AGH University of Science and Technology, Faculty of Energy and Fuels; al. Mickiewicza 30, 30-059 Krakow, Poland; e-mail: baranp@agh.edu.pl

(C) 2014 Authors. This is an open access publication, which can be used, distributed and reproduced in any medium according to the Creative Commons CC-BY 4.0 License requiring that the original work has been properly cited.

Received: 20 October 2013; accepted: 17 December 2013

\begin{abstract}
This paper summarises the results of methanol sorption on three selected coal samples from Polish collieries. These coals differ in terms of their degree of metamorphism (coal rank), petrography and elemental composition. It was found out that during the sorption of methanol, the sorption capacity is closely related to the structure of the coal surface and the amount of sorbed polar substance tends to decrease with the higher degree of metamorphism. Experimental data were plotted as isotherms. Empirical measurements were supported by thermodynamic analysis of aliphatic hydrocarbons sorption. The procedure is based on the Multisorption Model (MSM) designed for describing small molecules sorption in different types of carbonaceous materials (hard coals, lignites, active carbons).
\end{abstract}

Keywords: coal, sorption, methanol, multisorption model

\section{INTRODUCTION}

Hard coal is a heterogeneous organic rock with a complex physico-chemical structure (Mathews et al. 2011). Depending on the degree of metamorphism (coal rank), its elemental composition, physico-chemical properties, reactance and optical properties will vary (Krzyżanowski \& Żyła 2007). The strong dependence of these parameters on the coal rank indicates that coal types can be classified into categories displaying similar properties (Stachurski \& Żyła 1995). Most classifications are based on coal type categorisation depending on the inherent coal properties which determine its use as an energy source or a chemical component. Hard coals and solid products obtained in the process of coalification contain three basic components: organic substance, mineral substance and water, which are interacting both physically and chemically (Breus et. al 2006). The hard coal structure has received a great deal of researchers' attention which is in particular the consequence of its complexity and potential application as an energy source as well as a chemical component providing numerous organic compounds. In recent years the demand for high-grade coking coal and generator gas production has significantly decreased. Simultaneously there is a growing demand for hard coal to be used in flue gas treatment installations in coal-fired power stations in the purpose to remove carbon dioxide and nitrogen oxides. The production of active carbons from specific hard coals is also dynamically growing. Various chemical processes occurring on the coal surface involve the stage of inter-phase processes, including: oxidation, agglomeration, flotation, wetting and adsorption of gases and vapours (Takanohashi et al. 2000). Like many other materials, coal substance has the ability to adsorb low-molecule substances, such as water, methanol or gases. A large number 
of physical and chemical processes take place on the inter-phase surfaces where other processes originate. For that reason, a good insight into inter-phase phenomena is required to fully explain the involved processes mechanisms.

Adsorption is a fundamental surface phenomenon. It is recalled in descriptions of solids porosity and it must not be confused with absorption, for which an absorbed molecule is located within the sorbent (Jodłowski \& Wójcik 2013). Adsorption is typically employed in separation of gas mixtures, in water or flue gas treatment-hence its numerous applications in the petrochemical and pharmaceutical industry (Wang et al. 1997, Tamas et al. 2002). Moreover, adsorption is often the first stage in catalytic processes, including these occurring in the carbon adsorbent- methanol systems, on account of its potential use in thermal energy storage (Cortés et al. 2009). Such system can operate at temperatures below $273 \mathrm{~K}$ (adsorption cooling systems), so they offer better features than the mineral adsorbent-water systems (Buczek \& Wolak 2008).

\section{METHODS}

\section{Experimental setup and methodology}

Experimental tests were performed by the volumetric method (Orzechowska-Zięba \& Nodzeński 2008), with the use of fluid micro-burettes, at the temperature $303 \mathrm{~K}$. The use of a universal set of micro-burettes allows for collecting adsorption and desorption isotherms of vapours of polar substances, such as water or alcohols or non-polar compounds benzene, carbon tetrachloride, chloroform, ether, amines, in the whole range of relative pressures (Krzyżanowski \& Żyła 2007). The sorbate used in the experiment was methyl alcohol, which molecules exhibit a dual nature: the $-\mathrm{OH}$ group is polar while the methyl radix $-\mathrm{CH}_{3}$ is apolar. For that reason, the molecules of alcohol may be adsorbed both on polar and apolar sites, which suggests that $\mathrm{CH}_{3} \mathrm{OH}$ as an adsorbate should be categorised as sensitive to all sorption sites on the coal surface.

Underlying the theoretical analysis of the sorption isotherms is the copolymeric model of coal structure, assuming the coal composition with five major components (Milewska-Duda \& Duda 1993: 1) arene domains - rigid complex structures made of plates of condensed, interconnected benzene rings; the number of benzene rings in the plate and the number of plates within the domain being related to the coal rank;

2) interconnected chains - bulk structures of aliphatic, alicyclic or heterocyclic chains forming 3D structures (or connected with arene domains);

3) free chains - unconnected chains with statistical dominant longitude of several (typically 16) carbon atoms;

4) pores - empty spaces in coal bulk of different size, formed due to desorption of water, methane or carbon dioxide or after decomposition of functional groups in the direct proximity;

5) mineral admixtures - inclusions in the original coalbed, of different size and composition; typically their influence on the sorption process is neglected.

Compounds 1 and 2 form a macromolecular network: a bulk structure of limited rigidity, also referred to as the macromolecular phase, and filled with free chains. The term given to the unconnected chains is the "molecular phase of coal".

The thermodynamic analysis is based on the copolymeric model of coal. Formulas expressing the enthalpy and entropy of the sorption phenomena are derived using the Multiple Sorption Model (MSM) (Milewska-Duda et al. 2000), based on the Flory polymer solution theory (Flory 1953). The assumption is made that pores with the size comparable to that of sorbate molecules (submicropores) are of particular importance in the process of sorption, because the surface area is mainly included in this kind of pores.

Thus the sorption space is divided into several sub-systems:

- absorption - pores do not exist and are formed while the sorption proceeds, accompanied by the loss of cohesion energy of the coal substance;

- adsorption - pores having the molecule size diameter or larger are filled with molecules utilising the cohesion energy; in the case of larger pores, the additional model extension (LBET) is assumed;

- expansion - all phenomena taking place inside the pores having smaller diameter than sorption molecules; complex cohesion-adhesion energy relationships are encountered in this region. 
The sorption process is a priori divided into eleven sub-systems, depending on the pore size ( $R=0$ absorption, $R=1$ adsorption, as well as nine intermediate subsystems). The sorption system is characterised by the medium pore radius $R_{h a}$, which expresses the pore size for which the balance is achieved between the cohesion and adhesion energy.

Sorbate molecules do not fit perfectly into the pores and that is why the parameter $Z$ expresses the contact (interface) quality between molecules and the coal matter segments. $Z=1$ expresses the perfect contact (mostly in absorption) while $Z=0$ indicates the lack of contact. This parameter correcting the adsorption energy is divided between two regions: $Z_{A}$ - for pores smaller than $R_{h a}$ and $Z_{B}$ - for pores larger than $R_{h a}$.

The detailed thermodynamic analysis of the contact energy yields the pore volume $V_{h}$ and pore capacity $V_{h}^{\text {ad. }}$.

These geometrical parameters of the coal structure and the energy of sorption (cohesion and adhesion) enables to investigate the properties of the sorption systems.

The simulation experiment involves a number of steps, starting with the change of the selected parameter value of the sorption system (for example: $R_{h a}, Z_{A}, Z_{B}, V_{h}$ - see the footnotes under the Table 5). The simulated (theoretical) sorption isotherm is fitted to empirical points of the measured isotherm. Afterwards, parameters are changed following the comparison procedure until the theoretical isotherm is in very good agreement to the empirical one. Obviously all parameters have a thermodynamic rationale and the range of data having relevance to the coal sample with the given carbon content can be manipulated accordingly. Thus, parameters describing the coal composition (in terms of the copolymetric model) are unchangeable during the experiments.

\section{Test material}

Sorption tests were performed on three coal samples, from different coalbeds in different collieries. These samples were collected from Polish collieries: Pniówek, Sośnica and Jaworzno. The grain size was in the 0.125 to $0250 \mathrm{~mm}$ range. The parameters considered in the selection procedure included the carbon content and volatile mater content. The coal rank is strongly associated with the sorption properties of coal. The results of elemental analysis of investigated coal samples are summarised in Tables 1 and 2.

Table 1

Chemical and technological analyses of the studied coals

\begin{tabular}{|c|c|c|c|}
\hline Content [wt. \%] & Pniówek & Sośnica & Jaworzno \\
\hline $\mathrm{C}$ & 84.24 & 70.82 & 57.83 \\
\hline S (total) & 0.39 & 3.50 & 1.10 \\
\hline S (pyritic) & 0.01 & 3.20 & 0.71 \\
\hline $\mathrm{H}$ & 4.58 & 3.35 & 3.37 \\
\hline $\mathrm{N}$ & 1.52 & 1.28 & 0.87 \\
\hline $\mathrm{S}$ (ash) & 0.07 & 1.27 & 0.03 \\
\hline S (flameable) & 0.32 & 2.23 & 1.07 \\
\hline O & 4.58 & 6.29 & 11.30 \\
\hline Moisture Wa & 1.75 & 1.85 & 11.11 \\
\hline Ash Aa & 3.01 & 14.18 & 14.45 \\
\hline Volatile matter & 27.12 & 29.88 & 28.39 \\
\hline
\end{tabular}

Table 2

Petrographic analyses of the studied coals

\begin{tabular}{|c|c|c|c|}
\hline Macerals [wt. \%] & Pniówek & Sośnica & Jaworzno \\
\hline Vitrynite & 73 & 60 & 67 \\
\hline Liptinite & 7 & 9 & 5 \\
\hline Inertinit & 20 & 31 & 28 \\
\hline Mineral content & 1 & 14 & 11 \\
\hline
\end{tabular}

Coal from the colliery Pniówek (coal seam 360) has the highest carbon content (over 80\%) and the highest ash content in the range 3-4\%. Among lower rank coals, the coal from the colliery Sośnica (coal seam 413) contains about $70 \%$ of carbon and its ash content is considerable (about 14\%). Coal from the colliery Jaworzno, coal seam 209, is the lowest rank coal (carbon content $C=57.83 \%$ ) and has a large moisture content (11.11\%).

\section{Porosimetry measurements of coals}

A distinctive feature of porous materials, such as hard coals, is the occurrence of voids (pores) in the solid bulk material, which differ in size and shapes and are interconnected, forming intricate and irregular network. Porosity of the material $(P)$ is defined as the ratio of volume occupied by 
pores to the total volume of the porous substance. A porous structure affects the properties of coal materials, such as sorption capacity, mechanical, thermal, electric properties and reactance. Some of these properties (such as reactance) are affected only by the presence of open pores, in turn the thermal, mechanical and electric properties are associated with all pores: both open and closed. Of particular importance is the pore shape (ranging from narrow slits to spherical bubbles), their size distribution and spatial configuration within the material.

The mercury porosimetry methods were employed to determine the volume and surface areas of pores in the investigated coal samples. Porosimetric measurements were conducted with the Pascal 140 and Pascal 440 porosimeters. In mercury porosimetry methods the pores of the investigated material are penetrated by mercury under pressure. Mercury porosimetry is capable of handling a wide range of pores, both macropores and mesopores. This method is widely used for measuring the macroporosity of coals and other porous substances and can be employed in measurements of a portion of mezopores, the pore size range depending on the pressure generated by the porosimeter and the sample resistance.

Table 3 shows the results of porosimetric tests, providing the total volumes of pores and overall porosity for the three pore ranges: $5-7,500 \mathrm{~nm}$, 7,500-58,000 $\mathrm{nm}$ and 5-58,000 $\mathrm{nm}$.

Porosimetric test data suggest that coal from the colliery Jaworzno has the highest total porosity, while the lowest porosity is found for coal from the colliery Pniówek. It is apparent that the greatest proportion of the total pore volume are pores in the size range 5-10 $\mathrm{nm}$, in turn mesopores and macropores contribute in the smallest degree.
The coals density was measured with the Accu Pyc Micrometrics 1330 device. The use of helium enables to study porous media or those exhibiting intrinsic surface structure. As a noble gas, helium does not interact with other substances, does not get adsorbed at the ambient temperatures and at elevated temperatures and its molecule has the minimal size. That is why the use of helium allows even the smallest pores to be effectively penetrated, so the sample volume and density can be precisely determined. Table 4 summarises the real densities of investigated coal samples and calculated porosity data.

\section{Table 4}

The real densities of investigated coal samples and calculated porosity data

\begin{tabular}{|c|c|c|}
\hline Sample & Helium density $\boldsymbol{d}_{\mathrm{He}}\left[\mathbf{g} / \mathbf{c m}^{3}\right]$ & Porosity $\boldsymbol{f}_{\boldsymbol{v}}[\%]$ \\
\hline Pniówek & 1.26 & 3.24 \\
\hline Sośnica & 1.27 & 3.38 \\
\hline Jaworzno & 1.37 & 15.86 \\
\hline
\end{tabular}

\section{EXPERIMENTAL RESULTS}

The methanol sorption process was investigated in the relative pressure range from zero to that nearing the saturated vapour pressure value at $303 \mathrm{~K}$. Results of experimental testing of the coal sample from the colliery Pniówek are plotted in the graphic form in Figure 1. The isotherm resembles the type I isotherm (according to the IUPAC classification), also referred to as the Langmuir isotherm, which is characteristic of microporous adsorbents. The maximal sorption capacity of this coal is found to be $1.7 \mathrm{mmol} / \mathrm{g}$.

Figure 2 plots the sorption data obtained for coal from the colliery Sośnica. The isotherm is similar in shape to that obtained in the previous case. In the relative pressure range $p / p 0=0-0.05$ there is a sharp increase in the adsorption values

\section{Table 3}

Results of porosity measurements for coals from studied mines

\begin{tabular}{|c|c|c|c|c|c|c|}
\hline \multirow[b]{2}{*}{ Sample } & \multicolumn{2}{|c|}{ Range $(5-58,000 \mathrm{~nm})$} & \multicolumn{2}{|c|}{ Range $(5-7,500 \mathrm{~nm})$} & \multicolumn{2}{|c|}{ Range $(7,500-58,000 \mathrm{~nm})$} \\
\hline & $\begin{array}{l}\text { volume of pores } \\
\qquad\left[\mathrm{mm}^{3} / \mathbf{g}\right]\end{array}$ & $\begin{array}{c}\text { porosity } \\
{[\%]}\end{array}$ & $\begin{array}{l}\text { volume of pores } \\
\qquad\left[\mathrm{mm}^{3} / \mathrm{g}\right]\end{array}$ & $\begin{array}{c}\text { porosity } \\
{[\%]}\end{array}$ & $\begin{array}{l}\text { volume of pores } \\
\qquad\left[\mathrm{mm}^{3} / \mathrm{g}\right]\end{array}$ & $\begin{array}{c}\text { porosity } \\
{[\%]}\end{array}$ \\
\hline Pniówek & 25.32 & 3.24 & 21.80 & 2.81 & 3.42 & 0.44 \\
\hline Sośnica & 26.24 & 3.38 & 18.18 & 2.37 & 7.89 & 1.02 \\
\hline Jaworzno & 138.73 & 15.86 & 115.44 & 13.55 & 23.29 & 2.66 \\
\hline
\end{tabular}


for the two coal types. Besides, sorption capacity of these two coals appears to be very similar.

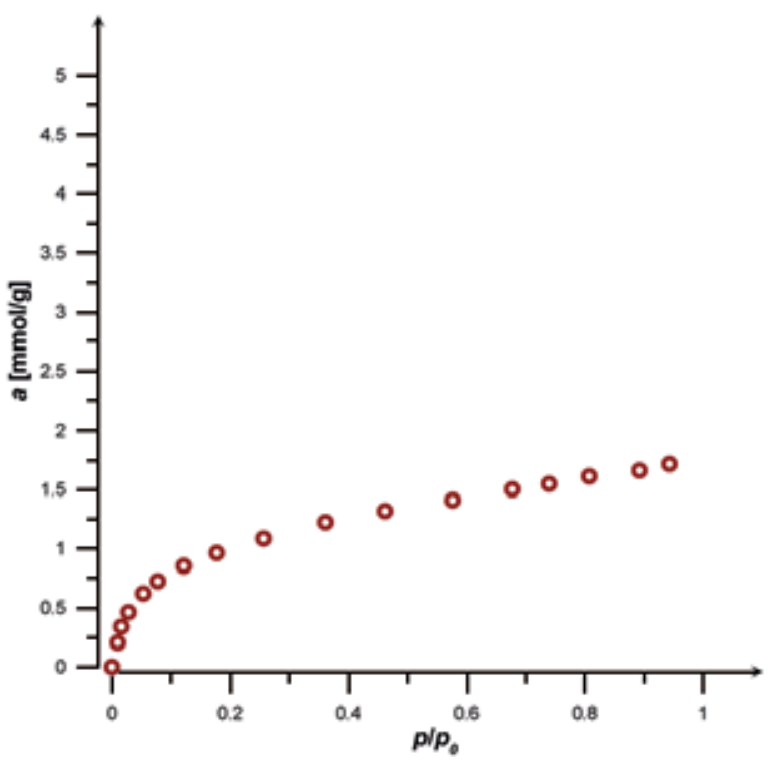

Fig. 1. Sorption isotherms of methanol on coal sample from the colliery Pniówek

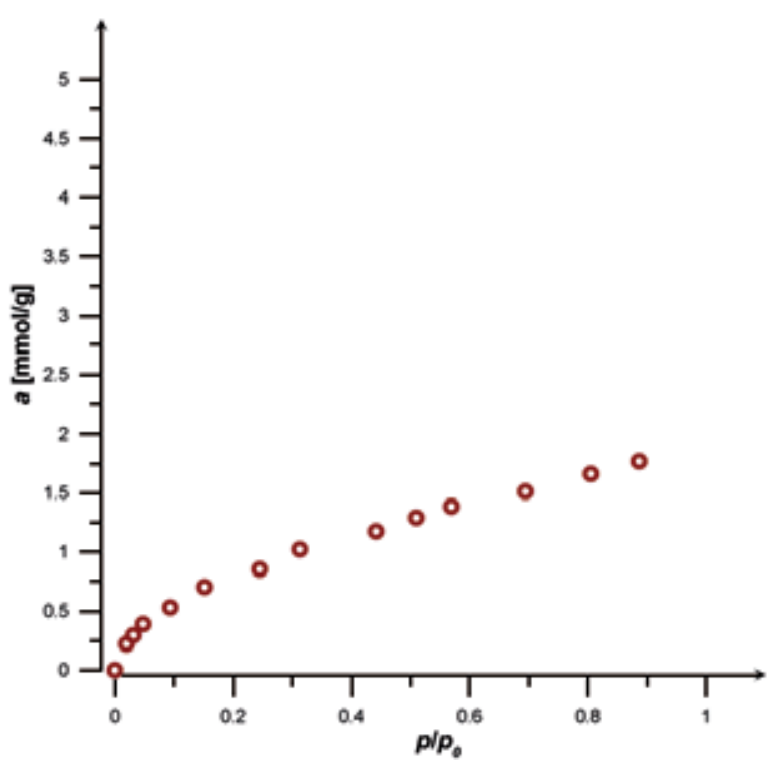

Fig. 2. Sorption isotherms of methanol adsorption on coal sample from the colliery Sośnica

In this case the shape of the isotherm (Fig. 3) approximates a straight line and does not resemble any particular isotherm pattern. It is worth to notice that the adsorption curve for this coal type is steeper than isotherms obtained for coals from the collieries Pniówek and Sośnica. At the relative pressure $p / p 0=0.7$, the adsorption of methanol on coal from the colliery Pniówek reaches the value
$1.5 \mathrm{mmol} / \mathrm{g}$, while under the same relative pressure the adsorption of methanol on coal from the colliery Jaworzno is found to be $3.7 \mathrm{mmol} / \mathrm{g}$. It is apparent that low rank coals (such as coal from the colliery Jaworzno, with carbon content $C=57.83 \%$ ), characterised by an expanded pore structure, high porosity (15.86\%) and high oxygen content $(11.30 \%)$ will sorb larger amounts of methanol than the other coals with the higher carbon contents (Pniówek - 84.24\%; Sośnica - 70.82\%). It is a generally known that hard coals as adsorbents display good sorption properties, particularly in relation to polar compounds (water, methyl alcohol, carbon dioxide and methane). This fact is well documented by numerous reports in the literature on the subject, demonstrating that low-rank coals will sorb considerable amounts of water and methanol molecules (Żyła \& Kreiner 2006, Kreiner et al. 2007).

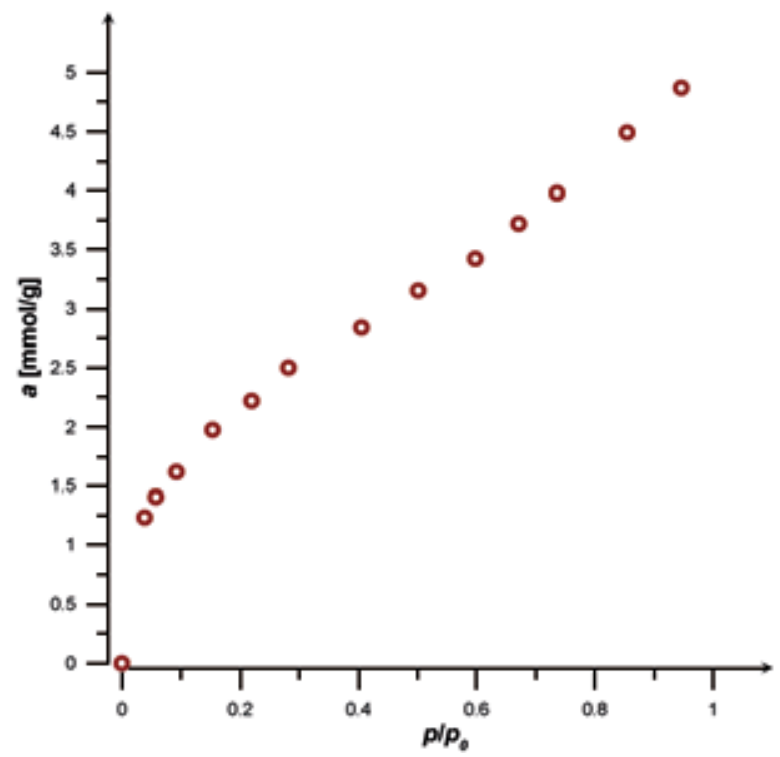

Fig. 3. Sorption isotherms of methanol sorption on the coal sample from the colliery Jaworzno

The presence of oxygen functional groups on the coal surface is important from the viewpoint of adsorption. The highest sorption capacity is reported for coals with high oxygen content and low -carbon content $(70-84 \%$ C). Medium-rank coals with the carbon content $(84-89 \%$ C) display low sorption capacity and these are mostly coals containing large contents of aliphatic and alicyclic hydrocarbons. The surface of these coals is found to be strongly hydrophobic. High rank coals (anthracites, semi-anthracites) exhibit a marked increase 
of the polar sorption sites, which is the consequence of their graphite-like structure, with numerous free pi-electrons and the presence of functional groups. The presence in the coal structure of functional groups: methoxy, hydroxyl, carboxyl, and carbon$\mathrm{yl}$, and ether gives apolar basic mass coal specified degree of polarity. For this reason, coal can be considered as a system of a dual capacity: hydrophilic and hydrophobic, which is reflected in amounts of sorbed substances. Methoxy groups (characteristic of lignin) are found mostly in peat and brown coals. Insignificant amounts of these functional groups are found in low-rank flame coals. Large amounts of carboxyl groups are found in brown coals. Oxygen atoms in carboxyl groups in lowrank coals are found in the amount up to $1.5 \%$ by weight. The number of carboxyl groups tends to decrease with the coal rank. Hard coals with the carbon content about $83 \%$ by weight do not contain carboxyl groups. Carbonyl groups occur in fuel coals, regardless of their carbonisation level, and their actual content tends to decrease with rank. Starting from medium-rank coals, the oxygen content in carbonyl groups falls below $1 \%(0.2-0.8 \%$ by weight). There are two types of hydroxyl groups: acidic phenol groups and $\mathrm{OH}$ groups, extended beyond the lamella surface and making the organic matter in coal basic (according to the Brønsted acid/base classification). Solid fuels with low carbon content (brown coals and low-rank hard coals) are abound in hydroxyl groups (nearely $0.9 \%$ of oxygen in hydroxyl groups). The higher the coal rank, the $\mathrm{OH}$ group content significantly decreases and in high-rank coals they are practically not present.

\section{MODELLING RESULTS}

Theoretical isotherms are fitted to empirical data as shown in Figures 4, 6 and 8. The original measured sorption isotherm points are recalculated using B-spline method in the aim of better capture the curve shape.

The theoretical total sorption isotherm (Fig. 4) is sufficiently well fitted with empirical points. Adsorption seems to be the dominant phenomenon in the entire process. In the medium range of relative pressures, predicted values tend to be slightly overestimated.

Figure 5 illustrates that the sorption of methanol on the coal sample $J$ is a complex phenomenon.
Two intermediate systems are filled with sorbate molecules giving rise to the expansion phenomena, yet all expansion subsystems are close to the adsorption system (for pore radii smaller and nearing the sorbate molecule size). That is why a relatively large proportion of molecules in the expansion subsystems does not cause any significant expansion of coal.

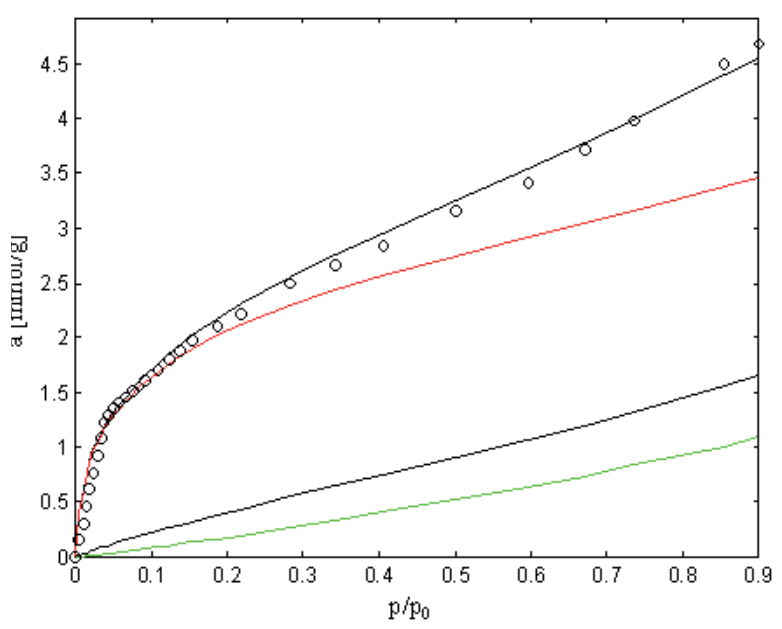

Fig. 4. Sorption isotherms of metanol on the J coal sample. Chart description: black circles - empirical isotherm, theoretical lines: black solid - isotherm of total sorption, black dash-dotted - expansion isotherm (cumulated with absorption), red solid - adsorption isotherm, green solid - absorption

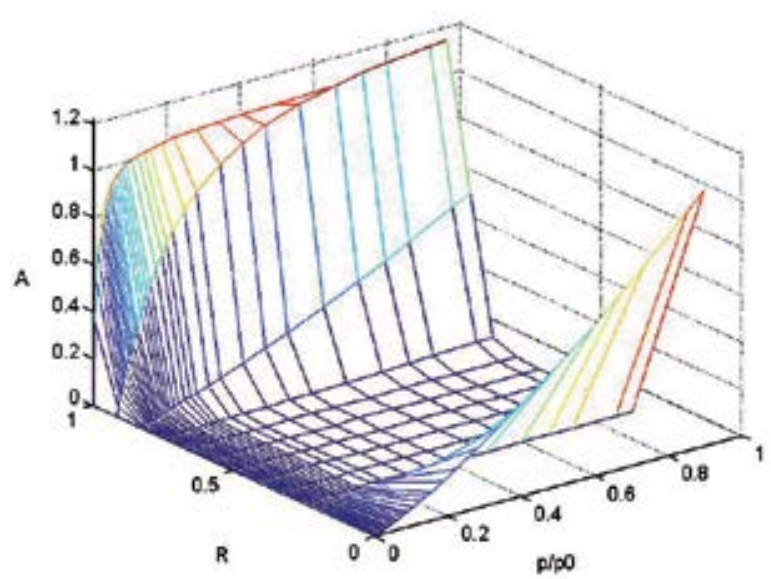

Fig 5. Multiple theoretical sorption isotherms of methanol on the $J$ coal sample in the subsystems. Axis description: $p / p_{0}-$ relative pressure, $R$ - pore radius relative to sorbate molecule size ( $R=0$ means absorption, $R=1$ means adsorption), $A$ sorption level [mmol/g]

Expansion in the system: coal sample $\mathrm{P}$ - methanol is of little significance. Absorption is enhanced in relation to the coal sample J. 


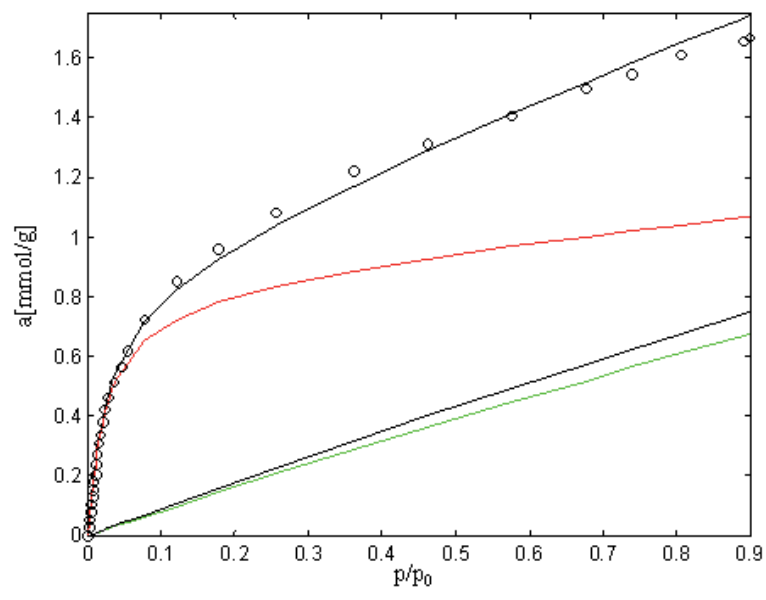

Fig. 6. Sorption isotherms of metanol on the P coal sample (chart and line description the same like on Figure 4)

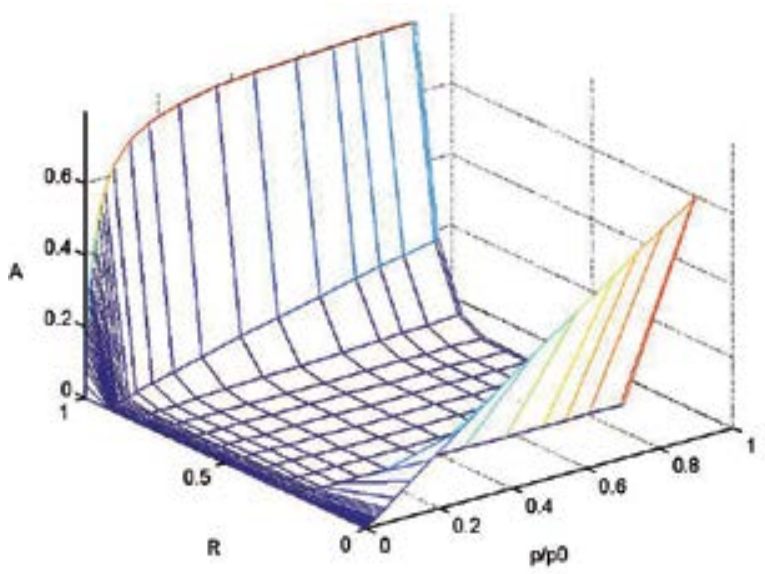

Fig. 7. Multiple theoretical sorption isotherms of methanol on the P coal sample in the subsystems (chart description the same like in Figure 5)

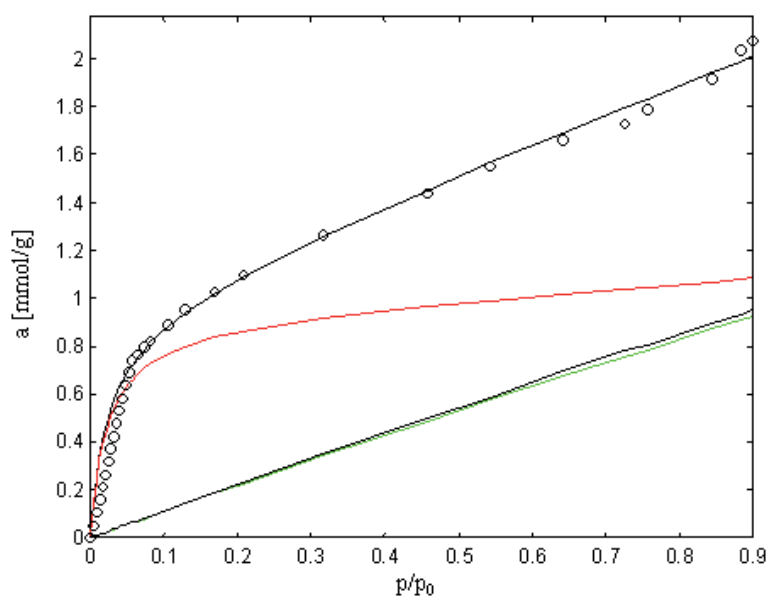

Fig. 8. Sorption isotherms of metanol on the $S$ coal sample (chart and line description the same like on Figure 4)
The methanol-coal J system (Fig. 7) is nearly dual. The weak isotherms of expansion are observed in the range of the relative radius comparable to the sorbate molecule size. Adsorption is still the dominant phenomenon, but absorption is also significant.

Expansion in the methane-coal S sample system is negligible (Fig. 9) and adsorption level is comparable to that registered in the higher range of relative pressures.

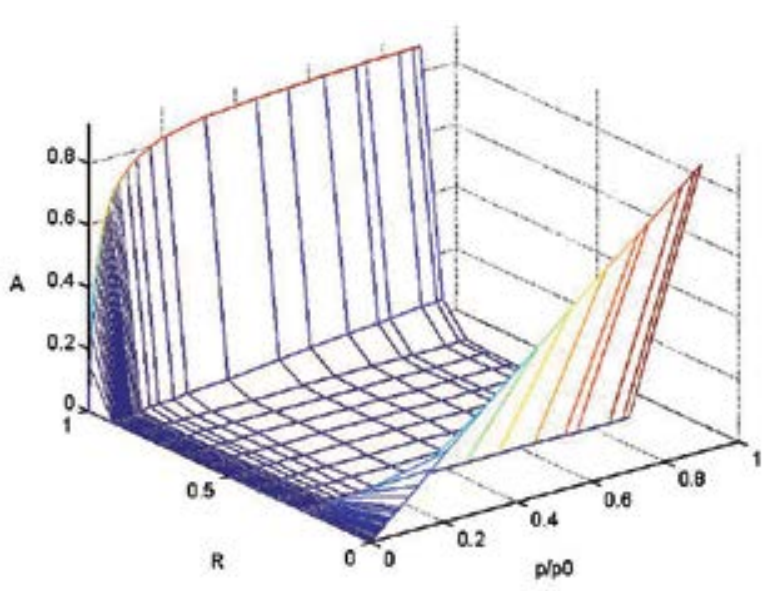

Fig. 9. Multiple theoretical sorption isotherms of methanol on the $S$ coal sample in the subsystems (chart description the same like in Figure 5)

The sorption system of methanol on the coal sample $S$ is actually dual. Expansion can be neglected and adsorption-absorption levels for $p / p 0=0.9$ are comparable.

Simulation experiments allow for estimation of several parameters of the coal structure and of the sorption system. Selected parameters of the sorption systems are summarised in Table 5.

\section{Table 5}

Chosen parameters of sorption systems obtained for methanol as a sorbate

\begin{tabular}{|c|c|c|c|}
\hline \multirow{2}{*}{ Parameter } & \multicolumn{3}{|c|}{ Coal sample } \\
\cline { 2 - 4 } & $\mathbf{J}$ & $\mathbf{P}$ & $\mathbf{S}$ \\
\hline$R_{h a}$ & 1.255 & 1.090 & 1.137 \\
\hline$Z_{A}$ & 0.92 & 0.98 & 0.78 \\
\hline$Z_{B}$ & 0.88 & 0.93 & 0.65 \\
\hline$V_{h}$ & 0.2328 & 0.1406 & 0.1751 \\
\hline$V_{h}^{\text {sub }}$ & 0.2317 & 0.1316 & 0.1699 \\
\hline$V_{h}^{\text {ad }}$ & 0.0457 & 0.0343 & 0.0379 \\
\hline
\end{tabular}


Table 5 cont.

\begin{tabular}{|c|c|c|c|}
\hline \multirow{2}{*}{ Parameter } & \multicolumn{3}{|c|}{ Coal sample } \\
\cline { 2 - 4 } & $\mathbf{J}$ & $\mathbf{P}$ & $\mathbf{S}$ \\
\hline$\chi_{\mathrm{ad}}$ & -4.61 & -3.72 & -3.8 \\
\hline$\chi_{\mathrm{ab}}$ & 4.80 & 3.17 & 3.71 \\
\hline$\delta_{C}$ & 31.7 & 23.5 & 31.50 \\
\hline exp/sorp(0.8) & 0.02296 & 0.01206 & 0.01553 \\
\hline abs/sorp(0.8) & 0.209 & 0.370 & 0.449 \\
\hline
\end{tabular}

Whole parameters are unitless, except volumes.

$R_{h a}$ - characteristic pore radius relative to molecule radius in which correction parameters $\mathrm{Z}$ change its property (description in the text above)

$Z_{A}$ - energy correction coefficient describes the contact of molecule and coal substance quality for pores smaller than $R_{h a}$

$Z_{B}$ - energy correction coefficient describes the contact of molecule and coal substance quality for pores larger than $R_{h a}$

$V_{h}$ - total pores volume depicted as a number of sorbate moles $[\mathrm{mol} / \mathrm{g}]$

$V_{h}^{\text {sub }}$ - volume of submicropores [mol/g]

$V_{h}^{\text {ad }}$ - volume of larger pores accessible for sorbate molecules $[\mathrm{mol} / \mathrm{g}$ ]

$\chi_{\text {ad }}$ - unitless energetic parameter describing adsorption energy (adsorption enthalpy $\left.\Delta H_{\mathrm{ad}}=\chi_{\mathrm{ad}} \cdot R T\right)$

$\chi_{\mathrm{ab}}$ - unitless energetic parameter describing absorption energy

$\delta_{C}$ - cohesion energy density; parameter describing the cohesion energy of coal substance, given by Hombach and van Krevelen

$\exp /$ sorp $(0.8)$ - expansion to sorption ratio by the relative pressure $p / p_{0}=0.8$

abs/sorp (0.8) - absorption to sorption ratio by the relative pressure $p / p_{0}=0.8$

It appears that the characteristic, relative pore radius $R_{h a}$ decreases with an increased carbon content and that pore size in which adhesion should overcome the cohesion force is larger than the molecule radius. This is the result of pore originating from the water and methane desorption process and of the irregular shape of a methanol molecule. Generally, methanol is regarded as an apolar substance, though the presence of hydroxyl groups makes the methanol molecules harder to fit into the pore.

Geometrical coefficients $Z_{A}$ and $Z_{B}$ vary with carbon content in an irregular pattern. Of particular interests are the values registered for the coal sample from the colliery Sośnica, where the contact between the sorbate molecule and the coal substance is very weak in the adsorption system, at the same time, however, the absorption level is the highest among the investigated systems. This may be the consequence of interactions between molecules from larger pores with an irregular shape and the molecules from the expansion and absorption systems.

The pore volume $V_{h}$ decreases with the carbon content, which is a well-established tendency (van Krevelen 1965). The analysis of micropore volume $V_{h}^{\text {sub }}$ reveals a similar tendency. The adsorption usage of pores (volume $V_{h}^{\text {ad }}$ ) is also reduced, but not as rapidly as the total volume $V_{h}$, hence the pore accessibility is better for coal samples with a higher carbon content. Similarly, the energy parameters $\chi_{\mathrm{ad}}, \chi_{\mathrm{ab}}$ and the Hombach parameter $\delta_{C}$ tend to decrease with the carbon content. It was to be expected, however, considering that $\chi_{\mathrm{ad}}, \chi_{\mathrm{ab}}$ are derived from the Hombach parameter. That means that the cohesion energy of coal is lower in coal samples with larger carbon content, as a consequence of an increase of the arene domains content and size.

Another interesting aspect is the absorption ratio, which is found to be significantly lower for the coal sample from Jaworzno, for which the carbon content is the lowest. It would seem reasonable to expect the larger contents of the molecular phase, being the bulk for absorption, but it appears that high-energy locations in pores and considerable energy of cohesion make the adsorption rather than absorption subsystem a more attractive option for sorbate molecules. The absorption ratio of the remaining coal samples follows the same tendency: it decreases with the increase carbon content. The expansion appears to be quite insignificant in all samples, though the expansion ratio decreases in the predictable manner: it is higher for coals with lower carbon contents and decreases with the growing carbon content.

\section{CONCLUSIONS}

The sorption tests conducted on coal samples from the collieries Pniówek, Sośnica and Jaworzno lead us to the conclusion that the sorption capacity of investigated coals with respect to methanol as a sorbate tends to decrease with the carbon content. The coal sample from the colliery 
Jaworzno, with the lowest carbon content (57.83\%) was found to have the highest porosity and the highest adsorption performance. Comparison of sorption isotherms suggests that porous structure of numerous hard coals exhibits the molecular sieve effect, hence larger amounts of methanol molecules sorbed on the porous coal from the colliery Jaworzno. It appears that the ability of coal to sorb methanol is associated both with coal porosity and micropore volume. A positive dependence is found between the amount of adsorbed methanol and the contents of elemental oxygen in coal. Sorption capacity of coal with respect to methanol is found to increase with the oxygen contents in coals, which seems to confirm the hypothesis assuming the importance of polar sites in the sorption processes. Test results give us a better insight into adsorption of polar substances and its major factors. Sorption test data will be utilised in design and optimisation of hard coal disposal processes. MSM is an effective tool to be used in studies of sorption in coals. Simulation modelling provides parameters that cannot be determined by other methods.

The research team adopted the procedure whereby the behaviour of different sorbates on the same coal samples was modelled to obtain reliable estimates of model parameters. Models take into account the complexity of the sorption phenomenon, and explain the absorption, adsorption and expansion mechanisms. Expansion was found to be a negligible phenomenon, while absorption in partially elastic materials, such as hard coals, could not be omitted. In consequence, it takes a long time before balance can be established in sorption measurements or during coalbed penetration by substances well absorbed in coal. All investigated samples exhibit this property and hence absorption has to be duly taken into account. Most conventional sorption theories (Langmuir, D-R, D-A, BET) should be regarded as comparative tools only as they fail to capture all aspects involved in sorption phenomena in coals.

The work has been carried out of the AGH UST project No 11.11.210.244.

\section{REFERENCES}

Breus I.P., Mishchenko A.A., Potashev K.A. \& Breus V.A., 2006. Description of organic compound vapor-phase sorption by geo sorbents: adequacy of the isotherm approximation. Colloids and Surfaces A, 276, 122-133.

Buczek B. \& Wolak E., 2008. Potassium hydroxide modified active carbon for adsorptive refrigerators. Adsorption: Journal of the International Adsorption Society, 14, 283-287.

Cortés F.B., Chejne F., Mejía J.M. \& Londoño C.A., 2009. Mathematical model of the sorption phenomenon of methanol in activated coal. Energy Conversion and Management, 50, 5, 1295-1303.

Jodłowski G. \& Wójcik M., 2013. Comparative analysis of sorption of small molecule hydrocarbons and polar substances in polish hard coals. Adsorption: Journal of the International Adsorption Society, 19, 813-819.

Kreiner K., Żyła M. \& Baran P., 2007. Zmiany właściwości węgli kamiennych w procesie wygrzewania $\mathrm{w}$ atmosferze powietrza i azotu. Gospodarka Surowcami Mineralnymi - Mineral Resources Management, 23, special issue 3, 167-174.

Krzyżanowski A. \& Żyła M., 2007. Characteristics of water, methanol and benzene vapours sorption properties of selected metamorphic types of hard coal. Gospodarka Surowcami Mineralnymi - Mineral Resources Management, 23, 4, 139-147.

Mathews J.P., van Duin A.C.T. \& Chaffee A.L., 2011. The utility of coal molecular models. Fuel Processing Technology, $92,4,718-728$.

Milewska-Duda J. \& Duda J., 1993. Mathematical modeling of sorption process in porous-elastic materials. Langmuir, 9, 3558-3566

Milewska-Duda J., Duda J., Jodłowski G.S. \& Kwiatkowski M., 2000. A model for multilayer adsorption in microporous materials. Langmuir, 16, 7294-7303.

Orzechowska-Zięba A. \& Nodzeński A., 2008. Sorption capacity of hard coals with respect to $\mathrm{C}_{6}$ to $\mathrm{C}_{8}$ hydrocarbons. Gospodarka Surowcami Mineralnymi - Mineral Resources Management, 24, 3/3, 245-254.

Stachurski J. \& Żyła M., 1995. The Effects of Water and Methanol Sorption on Surface of Hard Coals of Different Carbonization. Archives of Mining Sciences, 40, 3, 317-327.

Takanohashi T., Terao Y. \& Lini M., 2000. Sorption behaviors of methanol vapor by coal extracts and residues. Fuel, 79, 3-4, 349-353.

Tamas K., Vorholz J. \& Maurer G., 2002. Molecular Simulation of the High-Pressure Phase Equilibrium of the System Carbon Dioxide-Methanol-Water. Journal of Physical Chemistry B, 106, 7547-7553

Van Krevelen D.W., 1965. Chemical structure and properties of coal. Fuel, 44, 229.

Wang N., Sasaki M., Yoshida T. \& Kotanigawa T., 1997. Flow microcalorimetric study of methanol adsorption from n-hexane on coals. Energy \& Fuels, 11, 6, 1293-1298.

Żyła M. \& Kreiner K., 2006. Binarny charakter powierzchni węgla kamiennego. Górnictwo i Geoinżynieria, 30, 2, 19-34. 